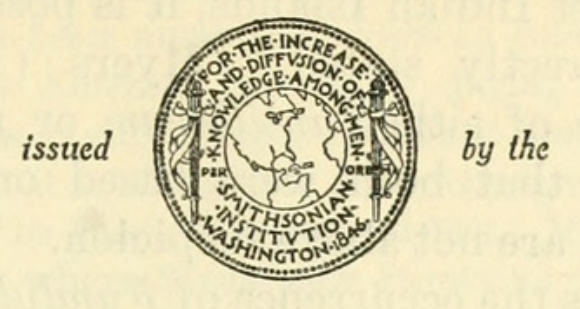

SMITHSONIAN INSTITUTION

U. S. NATIONAL MUSEUM

\title{
CYPRINODONT FISHES OF THE GENUS FUNDULUS IN THE WEST INDIES, WITH DESCRIPTION OF A NEW SUBSPECIES FROM CUBA
}

\section{By Luis René Rivas ${ }^{1}$}

Cyprinodont fishes of the genus Fundulus have been reported from the West Indies since Cuvier and Valenciennes (1846, p. 198) described $F$. fonticola from the fresh waters of Puerto Rico. More recently, Fowler (1916, p. 418) described $F$. antillarum from the Island of St. Martins. A third form ( $F$. grandis saguanus), described as new in the present paper, was collected by me in north-central Cuba. The cyprinodont described from western Cuba by Eigenmann (1903, p. 222, fig. 1) as Fundulus cubensis, is the type of Cubanichthys Hubbs (1926, p. 4), a genus allied to Chriopeops (Fowler, 1916, p. 425) of Florida and not closely related to Fundulus.

Until now most authors have doubted the existence of Fundulus in the West Indies. Fundulus fonticola is known only from the type specimens, despite extensive collecting in the waters of Puerto Rico (Evermann and Marsh, 1902; Nichols, 1929; Hildebrand, 1935, and others). Hildebrand (1935, p. 49) wrote about $F$. fonticola: "The type and presumably the only know specimen of $F$. fonticola, is reported to have been taken in a mountain spring in Puerto Rico. Poey's record (1881, p. 342) was based on Cuvier and Valenciennes, not on additional specimens as indicated by Evermann and Marsh (1902, p. 97). It is regarded as extremely doubtful whether M. Plée, the collector, actually obtained these fishes in Puerto Rico. Since he

\footnotetext{
1 This paper was prepared at the United States National Museum, at the time the author was engaged in research on West Indian fishes under a John Simon Guggenheim Latin American Fellowship. Marine Laboratory, University of Miami, Contribution No. 15.
} 
collected in other West Indian Islands, it is possible that the place of collection was incorrectly stated." Myers (1938, pp. 358, 360), doubted the existence of either antillarum or fonticola in the West Indies, pointing out that both were based on old collections, the locality data of which are not above suspicion. The present discovery definitely reestablishes the occurrence of Fundulus in the West Indies.

The following letter received by Dr. R. R. Miller from Dr. George S. Myers expresses his views regarding Fundulus in the West Indies.

There seems to be no good reason why Fundulus should not be found in the West Indies, since several of the species (heteroclitus, grandis, luciae, similis, majalis ) seem in many places to be as happy in salt water as in fresh. Cyprinodon, which is also partial to salt and inland alkaline waters, has reached Cuba, Hispaniola, Jamaica, the Bahamas, and Curaçao, and this migration has in part, at least, certainly been independent of former land connections. In my paper on West Indian Zoogeography (1938, p. 345) I pointed out the almost forgotten fact that the Challenger collected a Fundulus in a pelagic haul made in the midAtlantic.

Under these circumstances, it seems very strange that the only two records of Fundulus in the West Indies are based on old collections the data on which is open to suspicion. Fundulus fonticola Cuvier and Valenciennes (1846) was based on several specimens supposedly collected in Puerto Rico at a time when locality data were seldom given fully, and by a man (Plée) whose West Indian collections were very frequently mislabelled. When Jordan re-examined the types $(1887$, p. 526) he found all of them save the largest to be some sort of viviparous poeciliid; he says "apparently Gambusia." If they were Gambusia, it is certain they did not come from Puerto Rico, and the largest specimen, which alone was a Fundulus, probably did not, either. Fowler's F. antillarum, said to be from St. Martins, was based on types forming part of the van Rijgersma collection, which lay about in the Academy of Natural Sciences of Philadelphia for many years without being reported on. Other collections that similarly lay about for many years in the Academy, at a time when there was not an active ichthyological curator, had the data confused (witness Cope's supposed West African Fundulus nisorius, which is nothing but North American heteroclitus), and I seriously doubt the locality data of antillarum. I believe that I made an attempt at one time to see the types, but I am not sure. At least I know I never saw them, and I doubt their real distinctiveness from heteroclitus.

The fact that Rivas has discovered a new Fundulus in Cuba, however, puts a different light on antillarum, although $\mathrm{I}$ think it has no bearing on fonticola, the existence of which in Puerto Rico seems to be definitely disproved by Hildebrand's extensive work on that island. Now that we know that a Fundulus exists in Cuba, antillarum becomes slightly less difficult to believe, although little of the doubt regarding the data of those old Academy collections is dissipated by the Cuban discovery. My principal question is why such an aggressive fish as Fundulus, once in the West Indies, has not spread and become as ubiquitous as it is along coastal North America. I believe I expressed this same question in my 1938 Smithsonian paper, but an answer occurs to me. Excepting for Orestias in Lake Titicaca, the genus Fundulus inhabits colder water than any other genus of the family, and it scarcely enters the tropics at all. On the Pacific coast it reaches only to central Baja California, and on the Atlantic only to Yucatan. More southerly records are myths, or are based on Profundulus or other genera. Hubbs has shown the Cape San Lucas species to be nonexistent. 
The chief limiting factor has almost certainly been water temperature. It seems probable that there have been numerous overseas colonizations of Fundulus in the Antilles from North America, especially during the colder parts of the Pleistocene, for the genus is exceedingly abundant along the continental shores of the Gulf of Mexico, but it is likely that the warmer waters of the islands have proved to be unsuitable to these northerly fishes. It would be interesting to know whether the waters where Rivas' new Fundulus occurs is in general cooler than in other similar Cuban habitats. Cyprinodon would seem to be able to stand warmer water than Fundulus, for it has reached the southern Caribbean and exists in desert hot springs where no Fundulus would survive.

Through the assistance of Dr. Leonard P. Schultz, detailed measurements and counts of the type specimens of Fundulus fonticola were kindly sent from the Paris Museum by Dr. Paul Chabanaud. These show that the species was based on seven specimens 18.5 to 42 $\mathrm{mm}$. in standard length, of which only three $(22,23$, and $42 \mathrm{~mm}$.) belong to the genus Fundulus. These three specimens have 12 or 13 dorsal rays and 34 transverse rows of scales. They agree in these and other counts and proportions with forms of the $F$. heteroclitus group from northern Florida. The four remaining specimens have 7 or 8 dorsal rays and 32 transverse rows of scales, and they could very well be poeciliids of the genus Gambusia, as Jordan (1887, p. 526) suggested. Dr. Chabanaud also sent a photograph (pl. 14) of the largest specimen, which he has designated (in litt.) as the lectotype of the species. This photograph has been examined by Doctors Hubbs and Myers, and they agree that it represents a species of Fundulus.

Fundulus antillarum, known only from the two type specimens, is closely related to $F$. heteroclitus if it is not the same, as Fowler (1916, p. 420) originally indicated. The only differences he described are those of minor details of the coloration, the variation of which may have been due to the method and time of preservation. Hubbs (1926, p. 7 ) suggested that $F$. antillarum is a synonym of $F$. fonticola, which he provisionally recognized as a subspecies of $F$. heteroclitus. The Cuban Fundulus is regarded as only subspecifically distinct from $F$. grandis of southern Florida.

As discussed below in more detail, Fundulus probably reached the West Indies (Cuba) from southern Florida, during the Pleistocene, via Cay Sal Bank. It is to be expected that any Fundulus occurring in Puerto Rico ( $F$. fonticola) or St. Martins ( $F$. antillarum) would be related to $F$. grandis saguanus and $F$. grandis grandis from northcentral Cuba and southern Florida, respectively, rather than to $F$. heteroclitus, which inhabits the northern half of the peninsula of Florida.

The "mountain spring" in Puerto Rico, where $F$. fonticola is supposed to have been collected, does not seem to be the proper habitat for a Fundulus of the heteroclitus and grandis group. These forms in- 
habit shallow, salt, or brackish coastal waters where the bottom is composed of mud. It is not known whether $F$. antillarum was collected in salt, brackish, or fresh water.

The identities of $F$. fonticola and $F$. antillarum cannot be definitely established until a comparative study of specimens is made. During a recent visit to the Academy of Natural Sciences of Philadelphia I intended to study the type specimens of $F$. antillarum, but Henry W. Fowler, curator of fishes, was unable to locate them.

Methods of study.-Measurements are expressed as the number of times a given part is contained in the standard length, measured from the tip of the snout (anterior tip of upper lip) to the caudal base; the head length, from the tip of the snout to the extreme bony margin of the opercle; or in other base lengths such as the postorbital, interorbital, predorsal, and caudal peduncle. The postorbital was measured between the posterior fleshy margin of the orbit and the extreme bony margin of the opercle. The interorbital was considered as its least fleshy width. The predorsal length was measured from the tip of the snout to the origin of the dorsal fin. The length of the caudal peduncle is the distance between the end of the anal base and the middle of the caudal fin base. The width of the mouth was considered as the overall width, including the lips. All measurements were made and stepped off with fine-pointed dividers.

The last ray of the dorsal and anal fins was considered as a double ray split to the base. All pectoral and pelvic rays were counted as single rays. The transverse scale rows were counted from the upper end of the opercular margin to the caudal base; the longitudinal rows were counted between the dorsal and anal bases, not including the irregular rows immediately above the anal origin. Other measurements and counts used in this paper are self explanatory.

Throughout the description the measurements and counts of the holotype are given first, followed in parentheses by those of the female and male paratypes, separated by a semicolon.

Drs. Leonard P. Schultz and Robert R. Miller, of the U. S. National Museum, have kindly checked the composition of the manuscript, offering valuable suggestions. I am very grateful to the Sánchez family of Central Resulta, Sagua La Grande, for their kind hospitality and help during my stay in that region.

FUNDULUS GRANDIS SAGUANUS, new subspecies

Guasabolo

Plate 14

Description.-Greatest depth of body 3.6 (3.5 to $3.8 ; 3.2$ to 3.6 ) in standard length, 1.1 (1.1 or $1.2 ; 1.1$ or 1.2$)$ in head. Head 3.0 (2.8 to 


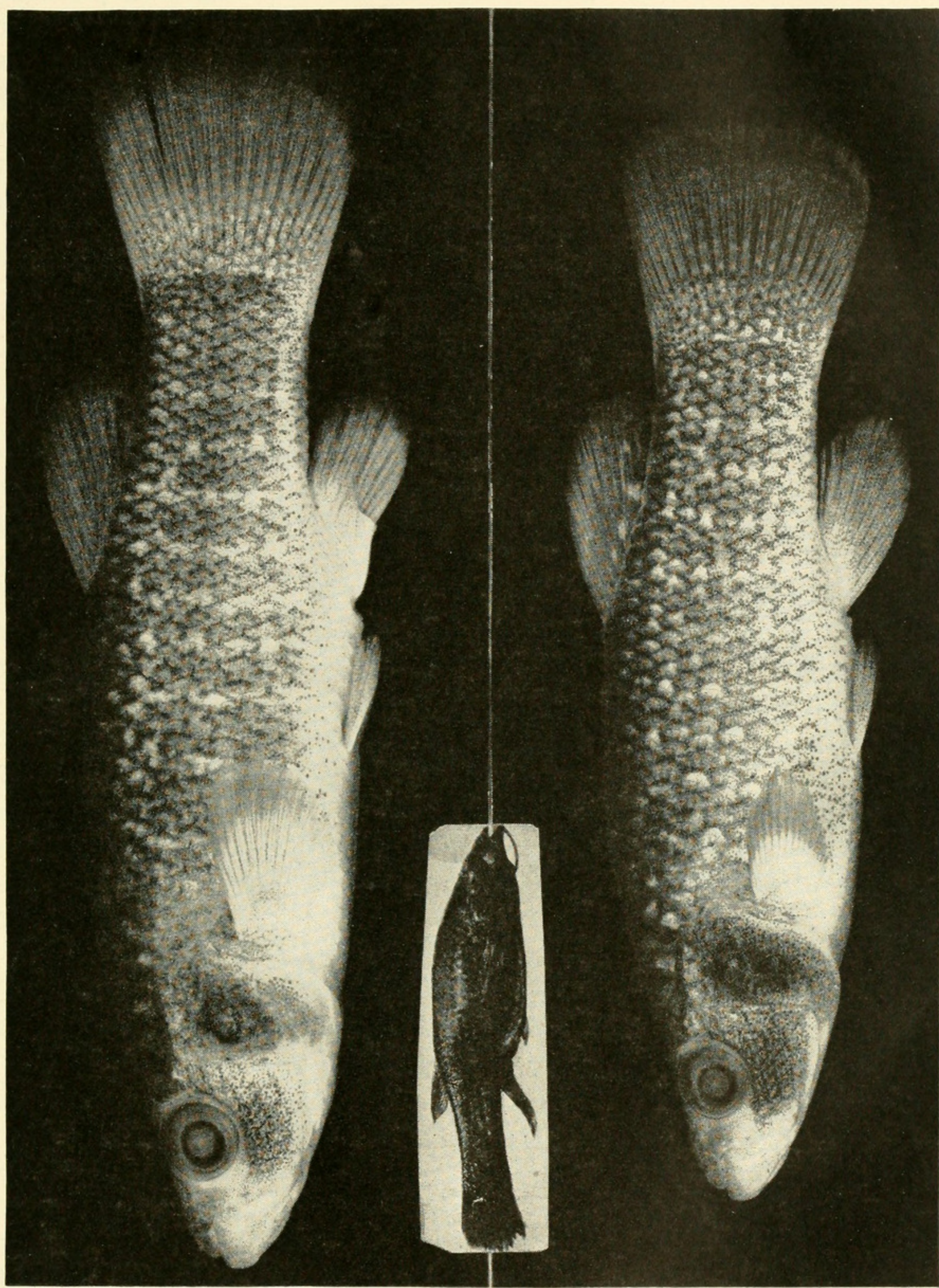

Fundulus grandis saguanus, new subspecies: Female holotype (left), $75 \mathrm{~mm}$. in standard length, and male paratype (right), $65 \mathrm{~mm}$., from Playa Uvero, Province of Las Villas, Cuba; photographed in Smithsonian Photographic Laboratory. Insert: Fundulus fonticola Cuvier and Valenciennes, from the lectotype, $42 \mathrm{~mm}$. in standard length; photograph courtesy of Dr. Paul Chabanaud, Musée d'Histoire Naturelle, Paris. 

$3.0 ; 2.7$ to 2.9 ) in standard length, its greatest width 1.0 (1.0 or 1.1 ; 1.0 or 1.1) in length of caudal peduncle. Origin of dorsal fin to tip of snout 1.5 ( 1.4 or $1.5 ; 1.4$ or 1.5$)$ in standard length. Origin of dorsal fin to caudal base 2.8 (2.6 to $2.9 ; 2.6$ to 2.8$)$ in standard length. Origin of anal fin to mandible tip, 1.4 (1.3 or $1.4 ; 1.3$ or 1.4 ) in standard length. Origin of anal fin to caudal base $2.9(2.8$ to $3.0 ; 2.9$ or 3.0$)$ in standard length. Insertion of pelvic fin to anus 2.5 ( 2.5 to $2.9 ; 2.7$ to 3.0$)$ in head. Distance between origins of dorsal and anal fins 1.2 (1.2 or 1.3; 1.2 or 1.3 ) in head. Length of caudal peduncle 4.5 ( 4.1 to $4.5 ; 4.1$ to 4.4) in standard length, 1.5 (1.3 to $1.5 ; 1.4$ to 1.6$)$ in head, 3.0 (2.7 to $3.0 ; 2.7$ to 2.9$)$ in predorsal length; its least depth $2.0(2.0$ to $2.2 ; 1.9$ to 2.1$)$ in head; $1.3(1.2$ to $1.4 ; 1.1$ to 1.3$)$ in its length. Horizontal diameter of orbit 4.3 (3.7 to $4.4 ; 4.0$ to 4.4 ) in head, 1.9 (1.5 to 1.9 ; 1.7 to 2.0$)$ in interorbital, 1.9 ( 1.5 to $1.9 ; 1.7$ to 2.0$)$ in postorbital. Interorbital 2.4 ( 2.2 to $2.4 ; 2.1$ to 2.3$)$ in head, $1.5(1.5$ or $1.6 ; 1.4$ to 1.6$)$ in length of caudal peduncle. Snout 3.0 (2.9 to $3.2 ; 3.0$ or 3.1$)$ in head. Width of mouth 2.7 ( 2.6 to $3.0 ; 2.7$ or 2.8$)$ in head, 1.1 (1.1 or $1.2 ; 1.1$ or 1.2) in interorbital.

Dorsal fin 1.4 (1.3 to $1.7 ; 1.2$ to 1.5 ) in head; anal 1.6 (1.6 to $1.9 ; 1.5$ to 1.7 ) ; pectoral 1.9 (1.8 to $2.0 ; 1.8$ to 2.1 ) ; pelvic 3.0 (2.8 to $3.0 ; 2.7$ to 3.0$)$; middle caudal rays 1.3 ( 1.3 or $1.4 ; 1.3$ or 1.4$)$.

Dorsal rays 11 (10 or 11 , usually $11 ; 10$ to 12 ); anal 10 (9 or 10 , usually $10 ; 9$ or 10 , usually 10 ) ; pectoral 16 (16 to 18 , usually 17 ; 17 or 18 , usually 17 ) ; pelvic 6 ; branched caudal 16 ( 16 to 18 ; 16 to 18 ). Scales in 32 (32 or $33 ; 32$ or 33 ) transverse rows, and 9 longitudinal rows; predorsal scales 16 (16 to $18 ; 16$ or 17$)$; suborbital scales in 5 ( 4 or $5 ; 4$ or 5 ) rows. Gill rakers 7 to 9 , usually 8 on lower limb of first arch.

Coloration as in Fundulus grandis grandis (Jordan and Evermann, 1896, p. 642). The specimens were killed and fixed in 10 percent formalin and later transferred to 70 percent alcohol.

Types.-The holotype, U.S.N.M. No. 132419, is an adult female 75 $\mathrm{mm}$. in standard length, collected by Luis René Rivas in a brackishwater channel at Playa Uvero, about $18 \mathrm{~km}$. northeast of Sagua La Grande (hence the name saguanus), Province of Las Villas, Cuba (latitude $22^{\circ} 51^{\prime}$ N., longitude $79^{\circ} 54^{\prime} 40^{\prime \prime}$ W.), on August 13, 1945. The paratypes, U.S.N.M. No. 132420, seined with the holotype, comprise 9 half-grown and adult females 38 to $65 \mathrm{~mm}$., and 5 adult males 49 to $65 \mathrm{~mm}$.

The type specimens have been deposited in the United States National Museum.

This subspecies differs from Fundulus grandis grandis in the deeper and shorter caudal peduncle, longer head, broader interorbital, fewer pectoral rays and scales, as shown in table 1 and the following key. 
1a. Least depth of caudal peduncle 1.5 to 1.8 , usually 1.6 or 1.7 in its length, which is contained 1.1 to 1.4 , usually 1.2 or 1.3 times in the head. Head 3.0 to 3.3 in standard length. Interoribital 1.6 to 2.0 , usually 1.7 to 1.9 in length of caudal peduncle. Pectoral rays 16 to 20 , usually 18 or 19 . Scales in 34 to 37, usually 35 or 36 transverse rows_______ Fundulus grandis grandis

1b. Least depth of caudal peduncle 1.1 to 1.4 , usually 1.2 or 1.3 in its length, which is contained 1.3 to 1.6 , usually 1.4 or 1.5 times in the head. Head 2.7 to 3.0 in standard length. Interorbital 1.4 to 1.6 , usually 1.5 or 1.6 in length of caudal peduncle. Pectoral rays 16 to 18 , usually 17 . Scales in 32 or 33 transverse rows

Fundulus grandis saguanus

The close relationship between Fundulus grandis grandis and $F$. grandis saguanus is shown by a critical comparative study of both forms. They more or less overlap in the distinguishing characters given in the above key, except for the transverse rows of scales, but table 1 indicates that more adequate material of saguanus will show overlap also in this character. For these reasons I think it best to consider saguanus as only subspecifically distinct from grandis, rather than to assign it full specific rank. Both forms have apparently the same habits and inhabit calm, shallow, coastal waters.

In comparing the new subspecies with specimens of $F$. grandis grandis from several localities (Florida Keys to Texas) along its range, it was found that grandis exhibits a number of variations of geographical significance. This subspecies may be shown to be a complex of local races if subjected to a critical study of variation throughout its range. The Cuban subspecies, saguanus, is most closely related to the race of grandis occurring in the Florida Keys.

The common ancestry of Fundulus grandis grandis and $F$. grandis saguanus is well established by their close relationship and vicarious distribution, and by their similar habits and habitat. These facts, correlated with the paleogeography of the region comprising southern Florida and north-central Cuba, suggest that the ancestors of saguanus probably migrated to Cuba from southern Florida, via Cay Sal Bank, during the Pleistocene.

Such a migration would not be difficult to conceive even during recent times, since the width of the Strait of Florida between the Keys and Cay Sal Bank (about 50 nautical miles) and that of Nicholas Channel between Cay Sal Bank and Cuba (about 20 nautical miles) is not very great. In my opinion, it would not be impossible for such a fish as Fundulus to cross these relatively narrow channels. But the fact that the populations of the Florida Keys and Cuba have differentiated, at least subspecifically, indicates that such an exchange of individuals is not actually taking place between the two regions. Much better conditions for this migration, however, existed during the Pleistocene when the level of the ocean was much lower, caused by waters impounded as ice on the poles. According to Daly (1934, p. 


\section{$2 \mathrm{BHL}$ Biodiversity Heritage Library}

Rivas, Luis Rene. 1948. "Cyprinodont fishes of the genus Fundulus in the West Indies, with description of a new subspecies from Cuba." Proceedings of the United States National Museum 98(3229), 215-222.

https://doi.org/10.5479/si.00963801.98-3229.215.

View This Item Online: $\underline{\text { https://www.biodiversitylibrary.org/item/53488 }}$

DOI: https://doi.org/10.5479/si.00963801.98-3229.215

Permalink: https://www.biodiversitylibrary.org/partpdf/52424

\section{Holding Institution}

Smithsonian Libraries

\section{Sponsored by}

Smithsonian

\section{Copyright \& Reuse}

Copyright Status: Public domain. The BHL considers that this work is no longer under copyright protection.

This document was created from content at the Biodiversity Heritage Library, the world's largest open access digital library for biodiversity literature and archives. Visit BHL at https://www.biodiversitylibrary.org. 